УДК $811.11-112$

DOI 10.52575/2712-7451-2021-40-2-253-263

\title{
Фразообразовательный потенциал древнеанглийских соматизмов
}

\author{
Мухин С.B. \\ Московский государственный институт международных отношений МИД России \\ Россия, 119454, Москва, пр. Вернадского, 76 \\ Email: s.muhin@inno.mgimo.ru
}

\begin{abstract}
Аннотация. Рассматрены лексикографическое представление ряда лексических соматизмов из расширенного списка Сводеша на предмет установления их сочетаемости. Выявленные словосочетания проанализированы $\mathrm{c}$ целью определения признаков фразеологизации. Словосочетания с соматическими компонентами, идентифицированные как фразеологизмы, распредеены в две основные группы в зависимости от идиоматического либо фразеоматического значения. Предлагается количественно выраженное представление фразообразовательного потенциала конкретных соматизмов.
\end{abstract}

Ключевые слова: соматизм, фразеология, древнеанглийский язык, фразообразование, список Сводеша.

Для цитирования: Мухин С.В. 2021. Фразообразовательный потенциал древнеанглийских соматизмов. Вопросы журналистики, педагогики, языкознания, 40 (2): 253-263. DOI: $10.52575 / 2712-7451-2021-40-2-253-263$

\section{Phrase-building potential of old english somatisms}

\author{
Sergey V. Mukhin \\ Moscow State Institute of International Relations of the Foreign Ministry of Russia, \\ 76 Vernadskogo av., Moscow, 119454, Russia \\ Email: s.muhin@inno.mgimo.ru
}

\begin{abstract}
The article is concerned with presenting the procedure and main results of the research aimed at determining the phrase-building potential of lexical somatisms in Old English. The research proceeds to scrutinize the lexicographic representation of a number of lexical somatisms taken from the extended 207-word Old English Swadesh list with a view to establishing their lexical combinability. The wordcombinations thus detected are analyzed in order to find out some markers of phraseologization. Those word-combinations with somatic components that are successfully identified as phraseological units, fall into two main groups in compliance with whether they feature either idiomatic or phraseomatic semantics, with the idiomatic group being the larger one and including the sentence-structured idioms of aphoristic nature. The numerical representation of the phrase-building potential of specific somatisms graphically demonstrates a substantially varying capability ofthe latter to form phraseologically tied word-combinations.
\end{abstract}

Keywords: somatism, phraseology, Old English, phrase-building, Swadesh list.

For citation: Mukhin S.V. 2021. Phrase-building potential of old english somatisms. Issues in Journalism, Education, Linguistics, 40 (2): 253-263 (in Russian). DOI: 10.52575/2712-7451-2021-40-2253-263 


\section{Введение}

В фразеологических подсистемах различных языков лексическим соматизмам принадлежит особая роль. Наличие соматической лексики в языках мира является одной из главных универсалий. При лексико-тематическом группировании названия частей тела образуют одну из трех главных групп наряду с зоонимической и ботанической лексикой [Богус, 2006]. Относясь, как правило, к основному словарному фонду языка и входя в ядро лексикона, лексические соматизмы активно участвуют во фразообразовании, при этом центральное место занимают названия наружных частей тела, функционально очевидных для человека [Шарманов, 2014].

Роль соматизмов во фразообразовании английского языка традиционно привлекает пристальное внимание исследователей. Из сравнительно недавних работ по данной тематике следует отметить диссертационные исследования К.Г. Завалишиной [2005], Т.С. Чумичевой [2010] и В.В. Подгорной [2015]. В то же время нельзя не обратить внимания на тот факт, что практически все работы по фразеологии ограничиваются рассмотрением материала современного английского языка. Исторический материал, как правило, остается за рамками исследования в силу его специфики.

Основным объективным препятствием к анализу древнеанглийской фразеологии следует признать ограниченность доступных данных об одном из важнейших свойств фразеологических единиц (ФЕ) - регулярности употребления в речи. Тем не менее даже тот ограниченный материал, который сохранился в письменных памятниках древнеанглийского языка, позволяет достаточно уверенно заявить, что «уже к древнему периоду в английском языке сложился определенный и достаточно большой фразеологический фонд, который лег в основу богатой фразеологической системы современного английского языка» [Дьякова, 2006, с. 27].

Компонентный состав фразеологизмов обычно кодирует концепты самого базового уровня [Langlotz, 2006, p. 136]. Исходя из того, что соматический код является наиболее древним из существующих [Красных, 2002] и, соответственно, соматическая лексика относится к одному из древнейших пластов словарного состава языка, будет логично сделать эмпирическое предположение, что значимость соматической лексики древнеанглийского языка для фразообразования была ничуть не меньше, чем в современном английском языке. На основе данного предположения в рамках настоящего исследования делается попытка выявить фразообразовательный потенциал базовых лексических соматизмов древнеанглийского языка.

Для достижения поставленной цели решается ряд конкретных задач: 1) определяется объем базовой соматической лексики; 2) выявляются словарно зафиксированные словосочетания, в составе которых имеются базовые соматизмы; 3) рассматриваются показатели устойчивости выявленных словосочетаний; 4) приводится краткий обзор устойчивых словосочетаний с соматическими компонентами; 5) делаются основные выводы исследования.

Основными методами настоящего исследования выступают фразеологическая идентификация, метод дефиниционного анализа, контекстуальный анализ и др.

\section{Определение объема базовой соматической лексики}

Первым шагом исследования должно быть определение понятий соматизма как такового и соматизма базового. Главной характеристикой лексического соматизма следует признать особенность его номинативной функции, а именно именование части тела. Семантика телесности - это категориальный признак всех соматизмов. Примечательным свойством лексических соматизмов является то, что в составе устойчивых словосочетаний они показывают ярко выраженную тенденцию к метафоризации значения, выступая таким образом необходимым строительным материалом идиоматики. Наличие хотя бы одного лексического компонента-соматизма автоматически превращает все устойчивое словосо- 
четание в соматический фразеологизм, значение которого не равняется сумме значений компонентов [Halupka-Rešetar, 2016].

Базовый соматизм - это лексема с соматической семантикой, которая принадлежит к основному словарному фонду языка и входит в ядро его лексикона, будучи одной из «разумно достаточного множества единиц», являющихся представителями лексической системы в целом [Стародубцева, 2018]. Более конкретно объем базовой соматической лексики определяется в рамках лексико-статистических исследований.

Для определения количества рассматриваемых соматизмов представляется обоснованным обратиться к хорошо известному в исследовательской практике списку Сводеша. В 1950-е гг. американский лингвист Моррис Сводеш разработал научный метод, который получил название глоттохронологии, или лексикостатистики. В основе данного метода лежит использование списка базовых понятий в различных языках, при помощи которого осуществляется генеалогическая классификация языков и вычисление времени распада праязыка [Бурлак, Старостин, 2005]. Существует несколько вариантов списка, различающихся объемом включаемой в них лексики. В целях большей репрезентативности языкового материала нами выбрана расширенная, 207-словная версия списка для древнеанглийского языка [The Indo-European, 2020]. В данной версии списка содержится некоторое количество соматизмов, среди которых преобладают антропные. С учетом важности принципа антропоцентризма в лексике, нами рассматриваются только они и не рассматриваются наименования частей тела животных, такие, как $\operatorname{horn}^{l}$ (рог), toezl (xвост), feper (перо, крыло).

В списке присутствуют следующие лексемы, называющие в основном внешние части человеческого тела: hyd (кожа), hor (волос, волосы), heafod (голова), еазе (глаз), тир (рот), top (зуб), tunzе (язык), (finzer) nкезl (ноготь), fot (нога, стопа), cneow (колено), hand (рука), sweora (шея), hrycз (спина, хребет), поsи (нос), breost (грудь), scanca (нога). Помимо перечисленных нами также анализируются существительные из списка, относящиеся к внутреннему строению организма: blod (кровь), ban (кость), pearmas (кишки), heorte (сердие), innop / wamb (живот, чрево) и lifer (печень). Таким образом, нами рассматривается фразообразовательный потенциал 23 лексем древнеанглийского языка с соматической семантикой. Следует отметить, что само это количество свидетельствует о важной роли этой лексико-семантической группы в основном лексическом фонде языка: 11 \% слов в списке Сводеша являются антропными соматизмами.

В словарно зафиксированных словосочетаниях наряду с некоторыми из приведенных лексем встречаются также другие соматизмы, не входящие в список Сводеша, например, существительные foran (лоб) и folm (ладонь). Представляется, что список соматизмов, участвующих в фразообразовательных процессах, можно было бы значительно расширить, однако в рамках настоящего исследования рассматриваются только базовые.

\section{Лексикографические данные о словосочетаниях с базовыми лексическими соматизмами}

Для изучения устойчивости словосочетаний с соматизмами необходимо собрать данные о сочетаемости последних в древнеанглийских текстах. Представляется, что есть два способа сбора таких данных: корпусный анализ текстов достаточно реперезентативного объема и изучение лексикографического представления соматизмов. В настоящем исследовании выбран второй способ. Фразеологических словарей древнеанглийского языка не существует, поэтому в качестве основного лексикографического источника нами выбран классический словарь древнеанглийского языка Дж. Босворта. Данный словарь создан в первой половине XIX в. и впоследствии был многократно переиздан. Мы пользуемся самым поздним изданием 1964 г. [Bosworth, 1964].

13д. и далее: орфография древнеанглийских слов приводится в соответствии с отечественной учебно-исследовательской и издательской традицией, за исключением особо указанных случаев. 
В словарных статьях, посвященных соответствующим лексемам с соматическим значением приводятся контекстуальные примеры употребления последних в памятниках письменности древнеанглийского языка. Анализируя данные примеры, можно составить представление о сочетаемости соматизмов.

Рассмотрим в качестве примера словарную статью, описывающую существительное breost (грудь) - один из востребованных во фразообразовании соматизмов, который в качестве стержневого компонента входит в состав многих ФЕ в различных языках, в том числе в современном английском.

В данной статье непосредственно за леммой и грамматическими сведениями о существительном среднего рода breost приводятся три значения слова, снабженные рядом иллюстративных примеров с переводом на латинский либо новоанглийский язык: 1) грудь как часть тела (pecus); 2) груди как молочные железы (ubera); 3) грудь как абстрактное воображаемое вместилище жизненных сил и чувств. Все примеры к первому и второму значению свидетельствуют о том, что они были основными, прямыми. Словосочетания с соматизмом breost в приведенных примерах не демонстрируют переосмысление семантики и иных показателей фразеологизации, как, например, в цитируемом словарем контексте из Евангелия от Луки, где в выделенном словосочетании с соматизмом breost все элементы используются в своем прямом значении:

forðam padazascumap on pamhiz cwepað: eadizesynt pauntymyndan \& innopas penecendun \& pabreost penesictun ${ }^{1}$

(ибо приходят дни, в которые скажут: «блаженны неплодные, и утробы неродившие, и сосцы непитавшие!» Лк. 23:29).

Иначе обстоит дело с третьим значением. В примерах 1-5 к нему можно отметить несколько сочетаний с предлогами: on breostum, inbreostum, innanbreostum. Данные предложно-именные комплексы объединены адвербиальным значением «в душе, в сознании». Пометы, указывающие на источники, говорят о том, что эти употребления данных словосочетаний в таком значении зафиксировано в различных источниках: в поэзии Кэдмона, в героико-религиозной поэме «Андрей» и в поэме «Генезис». Данный факт указывает на регулярность воспроизведения конкретно этих предложно-именных словосочетаний с переосмысленным значением по меньшей мере в письменной речи, что, безусловно, является важным показателем их фразеологического статуса.

Следует заметить, что не всегда приводимый в словаре контекст достаточен для четкого подтверждения или опровержения фразеологического статуса того или иного словосочетания. Обращение к первоисточнику всегда позволяет сделать это точнее. Так, в словаре можно видеть следующий пример:

Hie heora heáfdu slógan on ða wagas ${ }^{2}$

they struck their heads against the walls,Blickl. Homl. 151, 5.

Из данного примера нельзя понять, как употреблено словосочетание heafdu slozan on ðа wazas (бились головой о cтены) - в прямом значении или как образное выражение, которому в новоанглийской фразеологии соответствует ФЕ to batter / beat / butt / knock / runone'sheadagainsta (brick) wall со значением «прошибать лбом стену», «лезть на рожон» [Кунин, 1998, 365]. Анализ более широкого контекста из первоисточника дает возможность понять, что древнеанглийское словосочетание используется в буквальном смысле и не имеет фразеологического статуса:

\footnotetext{
13д. и далее: евангельские контексты цитируются в уэссекском диалектном варианте по [The Gospel, 1874].

${ }^{2}$ Приводится в орфографии источника.
} 
\& hie ba wurdon sona ablinde \& feollan to eorpan, \&heora heafdu slozan on pa wazas \& hie zrapodan mid heora handum on pa eorpan \& nystan hwyder hie eodan ${ }^{l}$

(и они тотчас ослепли и пали на землю и бились головой о стены и шарили руками по земле и не знали, куда идут).

Подобным же образом анализируются лексикографические данные о сочетаемости всех древнеанглийских соматизмов из списка Сводеша. В результате анализа зафиксировано наличие 68 словосочетаний с признаками фразеологической устойчивости.

\section{Структурно-семантические характеристики устойчивых словосочетаний с соматическим компонентом и их фразообразовательный потенциал}

Говоря о структурно-семантических характеристиках ФЕ с соматическими компонентами, представляется необходимым привести обзор их типов. Анализ показывает, что в целом для рассматриваемых ФЕ характерно большое разнообразие. Ими широко представлены как идиоматика, так и фразеоматика. Приведем конкретные примеры.

Большее распространение имеют идиомы, или собственно фразеологизмы. В таблице ниже приводятся примеры некоторых из них (табл. 1).

Древнеанглийские идиомы с соматическими компонентами

Old English idioms with somatic components

\begin{tabular}{|c|c|c|}
\hline Словосочетание & Буквальный перевод & Значение \\
\hline heafdes sezl & солние головы & глаз \\
\hline hydzebetan & возмещать икурой & подвергаться порке \\
\hline beleosanherum & лишиться волос & nocmapemb \\
\hline zan purh noedle eaze & пройти сквозь глаз игльl & сделать невозможное \\
\hline toð wið ted & зуб за зуб & в равной мере \\
\hline hand tomupe zedon & подносить руку ко рту & питаться \\
\hline on halre tunzan & на более здоровом языке & просто, доходчиво \\
\hline swa fot zestop & где ступала нога & где довелось быть \\
\hline binnancneowe & в колене & в родстве \\
\hline on sces hricz & на хребте моря & в открытом море \\
\hline hand ofer heafod & рука над головой & без усилий, легко, много \\
\hline blod azitan & пролить кровь & ранить, убить \\
\hline ban of banum & кость от кости & связанный, неотъемлемый \\
\hline of heortan & из сердца & из души, по природе \\
\hline fet and folma & ногии ладони & целиком, с руками и ногами \\
\hline
\end{tabular}

К идиоматическим единицам также относятся устойчивые афористические словосочетания со структурой законченного предложения, в том числе пословицы и поговорки, например:

${ }^{1}$ Blickling Homily 13, Assumption of Mary. 151, 4. Цитируется по [Klein, 1998, p. 126]. 
Đu ne miht wyrcan an har ðines feaxes hwit oððe blacc ${ }^{1}$

(не можешь ни одного волоса сделать белым или черным Мф. 5:36) ${ }^{2}$

Примечательно, что в подавляющем большинстве идиоматических словосочетаний соматизмы выступают стержневыми компонентами. Это обстоятельство во многом обусловлено тем, что все они являются субстантивными лексемами, играющими ключевую роль в номинации. Еще значительней роль соматизмов в образовании фразеоматически связанных словосочетаний. Ниже приводятся некоторые примеры фразеоматизмов (табл. 2).

Таблица 2

Table 2

Древнеанглийские фразеоматизмы с соматическими компонентами

Old English phraseomaticunits with somatic components

\begin{tabular}{|c|c|c|}
\hline Словосочетание & Буквальный перевод & Значение \\
\hline dead blod & мертвая кровь & запекшаяся кровь раны \\
\hline heafde foran & перед головы & лоб \\
\hline eazena zеsihp & вид глаз & вид \\
\hline aet his sylfes mupe zehyran & $\begin{array}{l}\text { в его собственном рту } \\
\text { услышать }\end{array}$ & усльшиать из чьих-л. собственных уст \\
\hline mid ðcere ylcan hand & этой самой рукой & собственноручно \\
\hline western wombe & плод чрева & плод чрева \\
\hline
\end{tabular}

Фразеоматические единицы не так многочисленны, как идиомы. Фразеоматизмам свойственно прямое значение компонентов, включая соматические. Если для идиом наиболее характерным выражением фразеологизации выступает семантическая трансформация компонентов и самой ФЕ в целом и часто яркая образность, то для фразеоматизмов ключевым показателем фразеологизации следует признать регулярность воспроизведения единиц в речи / тексте.

Анализ лексикографических данных показывает, что конкретные соматизмы характеризуются очень различным фразообразовательным потенциалом. Некоторые соматизмы зафиксированы в составе только одной ФЕ, например, лексема ban (кость) в приведенной выше идиоме:

Adam ða cwceð: Đis is nu ban of minum banum ond floesce of minum floesce ${ }^{3}$ (Адам тогда сказал: Теперь это кость от моей кости и плоть от моей плоти)

В этом случае следует говорить об ограниченном фразообразовательном потенциале данной конкретной соматической лексемы. Некоторые соматизмы способны входить во множество устойчивых сочетаний. Наиболее характерно это для предложно-именных сочетаний. Из общего числа рассматриваемых соматизмов наибольшей продуктивностью в этом смысле выделяется существительное hand (рука), которое может устанавливать устойчивую сочетаемость с большим числом различных предлогов, местоимений и существительных. При этом образуются чаще ФЕ с идиоматически переосмысленным значением. Ниже приводятся примеры ФЕ с соматизмом hand (табл. 3).

\footnotetext{
${ }^{1}$ Цитируется по [Thorpe, 1843, 482].

${ }^{2}$ [Библия онлайн, 2020].

${ }^{3}$ Цитируется по [Crawford, 1922].
} 
Древнеанглийские фразеологические единицы с соматизмом hand

Old English phraseologicalunits with the somatism hand

\begin{tabular}{|c|c|c|}
\hline Словосочетание & Буквальный перевод & Значение \\
\hline cethanda & в руке & в подчинение \\
\hline mid bradre hand & с широкой рукой & ладонью, плашмя \\
\hline ১a neh handa & близкой рукой & близко, подрукой \\
\hline hand on handa & рука в руке & рукаобруку \\
\hline aet hoebbendre handa & при имеющей руке & споличнылм \\
\hline hond and rond hebban & рукуи щитт поднимать & $\begin{array}{l}\text { быть достаточно взрослым, } \\
\text { стать воином }\end{array}$ \\
\hline $\begin{array}{l}\text { on zehwaeðre hond / on } \\
\text { cezðera hand }\end{array}$ & на обе руки & с обеихсторон \\
\hline wið celce hand & с каждой руки & вовсестороны \\
\hline unnendre hand & дарующей рукой & охотно, добровольно \\
\hline polian ðcera handa & потерять руки & $\begin{array}{l}\text { лишиться рук через отрубание } \\
\text { как наказание }\end{array}$ \\
\hline cethandum & в руках & от рук, посредством \\
\hline handumandfotum & руками и ногами & по рукам и ногам \\
\hline behandum zebindan & по рукам связывать & связывать по рукам \\
\hline zemoenumhondum & общими руками & совместно \\
\hline onhand/ underhonde & в руке / под рукой & во владении, в подчинении \\
\hline tohanda / under hand & в руку / под руку & во владение, в подчинение \\
\hline
\end{tabular}

Наряду с соматизмами, способными активно участвовать во фразообразовании, такими как hand (рука), heafod (голова), тир (рот), в числе соматических лексем из списка Сводеша обнаруживаются единицы, которые не имеют устойчивой сочетаемости: eare (ухо), scanca (нога), поsи (нос), lifer (печень), pearmas (кишки), sweora (шея). Вместе с тем возможны словосочетания с признаками устойчивости, в составе которых находятся по два соматических компонента, например:

Đoet iren ne cume on hare ne on nazle

(не стричься и не бриться, букв.: железо не касается ни волоса, ни ногтя)

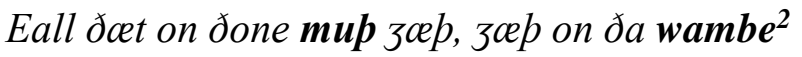

(всё, входящее в уста, проходит в чрево и извергается вон Мф. 15:17)

Всего из 23 соматизмов, входящих в список Сводеша, в той или иной степени способность к фразообразованию отмечается у 19. Ниже приводятся данные по каждой единице, полученные в результате рассмотрения лексикографической репрезентации соответствующих лексем в Bosworth-Toller Anglo-Saxon Dictionary и анализа соответствующих контекстов с данными лексемами в тектах-источниках (табл. 4).

\footnotetext{
${ }^{1}$ Цитируется по [Magennis, McWilliams, 2012, p. 174].

${ }^{2}$ Цитируется по [Thorpe, 1843, p. 122].
} 
Количество словосочетаний с признаками фразеологизации, образуемых древнеанглийскими соматизмами из списка Сводеша

The number of phraseologized word-combinations

formed by Old English somatisms from the Swadesh list

\begin{tabular}{|c|c|c|}
\hline Соматизм & Значение & Количество словосочетаний \\
\hline hyd & кожа, икура & 2 \\
\hline hoer* & волос, волосы & 3 \\
\hline heafod & голова & 7 \\
\hline eaze & глаз & 4 \\
\hline$m u p^{*}$ & pom & 6 \\
\hline top & $3 у б$ & 2 \\
\hline tunze & язык & 3 \\
\hline (finzer)noezl* & ноготь & 1 \\
\hline fot & нога, стопа & 5 \\
\hline cneow & колено & 3 \\
\hline hand & рука & 23 \\
\hline eare & $y x o$ & 0 \\
\hline scanca & нога & 0 \\
\hline sweora & шея & 0 \\
\hline hrycz & спина, хребет & 2 \\
\hline nosu & нос & 0 \\
\hline breost & груды & 1 \\
\hline blod & кровь & 3 \\
\hline ban & кость & 1 \\
\hline pearmas & кишки & 0 \\
\hline heorte & сердие & 1 \\
\hline innop / wamb* & живот, чрево & 2 \\
\hline lifer & печень & 0 \\
\hline
\end{tabular}

*Примечание: общее число словосочетаний меньше, чем сумма словосочетаний с конкретными соматизмами, так как слова, отмеченные астериском, входят в состав устойчивых словосочетаний попарно (см. примеры выше).

Количественный подсчет фразеологизмов, образуемых соматическими лексемами, осложняется структурной вариативностью словосочетаний. Так, контекстуальные словосочетания с существительным hrycз (спина, хребет) характеризуются различиями грамматической структуры и лексического состава, но демонстрируют единство семантики, позволяющее признать их аллофразами одной фраземы со значением «на море, в открытом море, по бурному морю». В сочетании с различными предлогами, существительными sce (море), waeter (вода), уд (волна) и лексемой breon ${ }^{1}$ элемент hrycз выступает как стержневой

${ }^{1} \mathrm{C}$ учетом данных топонимики и диалектной вариативности носового сонанта этимологи- 
неподменяемый компонент фраземы, контекстуально реализуемой вариантами: on sas hricz, ofersas hryc3, oferwateres hryc3, onwateres hricz,oferbreone hryc z, yða hrycz. Таким образом, все перечисленные словосочетания учитываются как одна фразеологическая единица.

\section{Заключение}

Изучение фразообразовательного потенциала соматизмов в древнеанглийском языке в рамках настоящего исследования позволяет сделать ряд выводов:

1) соматизмы-существительные занимали важное место в основном лексическом фонде. Каждое девятое слово в расширенном списке Сводеша является антропным соматизмом;

2) существующее лексикографическое представление соматических единиц позволяет создать достаточно широкую картину их сочетаемости;

3) с помощью метода фразеологической идентификации представляется во многом возможным определить фразеологический статус словосочетаний с компонентамисоматизмами;

4) соматизмы в целом показывают достаточно высокий фразообразовательный потенциал. В среднем каждый соматизм образует по три устойчивых словосочетания. При этом способность конкретных единиц к образованию устойчивой фразеологической связи сильно разнится. Шесть слов из общего числа 23 соматизмов $(26 \%)$ вообще не обнаруживаются в фразеологических словосочетаниях. В то же время существительное hand (рука) образует каждое третье из общего числа ФЕ с компонентами-соматизмами.

\section{Список источников}

1. Библия онлайн. 2020. URL: https://old.bibleonline.ru/ (дата обращения: 10.10.2020).

2. Кунин А.В. 1998. Большой англо-русский фразеологический словарь. М., Живой язык, $944 \mathrm{c}$.

3. Bosworth J. 1964. An Anglo-Saxon Dictionary: Based on the Manuscript Collections of the Late Joseph Bosworth. London, Oxford University Press, 1302 p.

4. Crawford S. J. 1922. The Old English Version of the Heptateuch, Ælfric's Treatise on the Old and New Testament and his Preface to Genesis, EETS o.s. London, 160 p.

5. The Gospel according to Saint Luke in Anglo-Saxon and Northumbrian Versions. 1874. Ed. by W.W. Skeat. Cambridge, $252 \mathrm{p}$.

6. The Indo-European Wordlists. 2020. Available at: https://www.cs.rice.edu/ nakhleh/CPHL/iewordlist-07.pdf (accessed: 18.09.2020).

\section{Список литературы}

1. Богус 3.А. 2006. Соматизмы в разносистемных языках: семантикословообразовательный и лингвокультурологический аспекты (на материале русского, адыгейского и английского языков). Автореф. дис. ... канд. филол. наук. Майкоп, 28 с.

2. Бурлак С.А., Старостин С.А. 2005. Сравнительно-историческое языкознание. М., Академия, 432 с.

3. Дьякова Н.А. 2006. Теоретические и методологические основы исторического изучения английской фразеологии. Культура народов Причерноморья, 76: 25-29.

4. Завалишина К.Г. 2005. Концептосфера «человек телесный» в языке русского, немецкого и английского песенного фольклора. Автореф. дис. ... канд. филол. наук. Курск, 19 с.

5. Красных В.В. 2002. Этнопсихолингвистика и лингвокультурология. М., ИТДГК Гнозис, 284 с.

ческий анализ позволяет определить это слово как существительное в исходной форме bream со значением «возвышенность, открытая ветру» [Johnston, 1915, p. 167], т.е. «высокая волна». 
6. Подгорная В.В. 2015. «Наивная анатомия» в английской языковой картине мира. Дис. ... докт. филол. наук. Спб., 226 с.

7. Стародубцева Ю.А. 2018. Параметрическое ядро лексики русского языка по данным "Словаря русского языка в 4-х томах" под редакцией А.П. Евгеньевой (2-ое изд.). Дис. ... канд. филол. наук. Воронеж, 276 с.

8. Чумичева Т.С. 2010. Фразеологизмы с компонентами-соматизмами в национальных вариантах английского языка (на материале британского и американского вариантов). Автореф. дис. ... канд. филол. наук. Нижний Новгород, 24 с.

9. Шарманов В.В. 2014. Соматизм как компонент фразеологической единицы русского и немецкого языков. Universum: Филология и искусствоведение, 10 (12). URL: https://7universum.com/ru/philology/archive/category/10-12 (дата обращения: 16.09.2020).

10. Halupka-Rešetar S. 2016. Somatisms with the Lexemes Láb in Hungarian, Noga in Serbian, and Leg/Foot in English. Acta Universitatis Sapientiae, Philologica, 8, 2: 21-34.

11. Johnston J. B. 1915. The Place-names of England and Wales. London, $556 \mathrm{p}$.

12. Klein T.P. 1998. The 'Coarser' Senses in Old English: a Study of the Old English Verbs of Tasting, Smelling, Touching and Perceiving. Toronto, $240 \mathrm{p}$.

13. Langlotz A. 2006. Idiomatic Creativity: A Cognitive-linguistic Model of Idiomrepresentation and Idiom-variation in English. Philadelphia, John Benjamins Publishing, 325 p.

14. Magennis H., McWilliams S. 2012. Saints and Scholars: New Perspectives on Anglo-Saxon Literature and Culture in Honour of Hugh Magennis. DS Brewer, 280 p.

15. Thorpe B. 1843. The Sermones Catholici, Or Homilies: In the Original Anglo-Saxon, with an English Version. Vol. 1. London, 624 p.

\section{References}

1. Bogus Z.A. 2006. Somatizmy v raznosistemnykh yazykakh: semantikoslovoobrazovatel'nyy i lingvokul'turologicheskiy aspekty (na materiale russkogo, adygeyskogo i angliyskogo yazykov) [Somatisms in multi-system languages: semantic-educational and linguoculturological aspects (based on the material of the Russian, Adyghe and English languages)]. Abstract dis. ... Cand. philol. sciences. Maykop, 28 p.

2. Burlak S.A., Starostin S.A. 2005. Sravnitel'no-istoricheskoe yazykoznanie [Comparative Historical Linguistics]. M., Publ. Akademiya, 432 p.

3. D'yakova N.A. 2006. Teoreticheskie i metodologicheskie osnovy istoricheskogo izucheniya angliyskoy frazeologii [Theoretical and methodological foundations of the historical study of English phraseology]. Culture of Black Sea People, 76: 25-29.

4. Zavalishina K.G. 2005. Kontseptosfera "chelovek telesnyy" v yazyke russkogo, nemetskogo $i$ angliyskogo pesennogo fol'klora [The concept of "bodily man" in the language of Russian, German and English song folklore]. Abstract dis. ... Cand. philol. sciences. Kursk, 19 p.

5. Krasnykh V.V. 2002. Etnopsikholingvistika i lingvokul'turologiya [Ethnopsycholinguistics and cultural linguistics]. M., Publ. ITDGK Gnozis, 284 p.

6. Podgornaya V.V. 2015. "Naivnaya anatomiya" v angliyskoy yazykovoy kartine mira ["Naive Anatomy" in the English Language Picture of the World]. Dis. ... Cand. dokt. sciences. Spb., 226 p.

7. Starodubtseva Yu.A. 2018. Parametricheskoe yadro leksiki russkogo yazyka po dannym "Slovarya russkogo yazyka v 4-kh tomakh" pod redaktsiey A.P. Evgen'evoy (2-oe izd.) [The parametric core of the vocabulary of the Russian language according to the "Dictionary of the Russian language in 4 volumes" edited by A.P. Evgenieva (2nd ed.)]. Dis. ... Cand. philol. sciences. Voronezh, 276 p.

8. Chumicheva T.S. 2010. Frazeologizmy s komponentami-somatizmami v natsional'nykh variantakh angliyskogo yazyka (na materiale britanskogo i amerikanskogo variantov) [Phraseologisms with Somatism Components in National Variants of the English Language (Based on the British and American Variants)]. Abstract dis. ... Cand. philol. sciences. Nizhniy Novgorod, 24 p.

9. Sharmanov V.V. 2014. Somatizm kak komponent frazeologicheskoy edinitsy russkogo i nemetskogo yazykov [Somatism as a component of the phraseological unit of the Russian and German languages]. Universum: Filologiya i iskusstvovedenie, 10 (12). Available at: https://7universum.com/ru/philology/archive/category/10-12 (accessed: 16.09.2020).

10. Halupka-Rešetar S. 2016. Somatisms with the Lexemes Láb in Hungarian, Noga in Serbian, and Leg/Foot in English. Acta Universitatis Sapientiae, Philologica, 8, 2: 21-34. 
11. Johnston J. B. 1915. The Place-names of England and Wales. London, 556 p.

12. Klein T.P. 1998. The 'Coarser' Senses in Old English: a Study of the Old English Verbs of Tasting, Smelling, Touching and Perceiving. Toronto, $240 \mathrm{p}$.

13. Langlotz A. 2006. Idiomatic Creativity: A Cognitive-linguistic Model of Idiomrepresentation and Idiom-variation in English. Philadelphia, John Benjamins Publishing, 325 p.

14. Magennis H., McWilliams S. 2012. Saints and Scholars: New Perspectives on Anglo-Saxon Literature and Culture in Honour of Hugh Magennis. DS Brewer, $280 \mathrm{p}$.

15. Thorpe B. 1843. The Sermones Catholici, Or Homilies: In the Original Anglo-Saxon, with an English Version. Vol. 1. London, 624 p.

\section{ИНФОРМАЦИЯ ОБ АВТОРЕ}

Мухин Сергей Владимирович, кандидат филологических наук, доцент, доцент кафедры английского языка № 1 Московского государственного института международных отношений МИД России, г. Москва, Россия

\section{INFORMATION ABOUT THE AUTHOR}

Sergey V. Mukhin, Candidate of Philology, Associate Professor, Associate Professor of the Department of English Language No. 1 of the Moscow State Institute of International Relations of the Ministry of Foreign Affairs of Russia, Moscow, Russia 